\title{
Exiliados en la "edad de oro". Redes y políticas culturales del exilio gallego en el campo editorial argentino de la década del cuarenta: publicaciones periódicas, colecciones y editoriales
}

\section{Exilados na "idade de ouro". Redes e políticas culturais do exílio galego no campo editorial argentino da década de quarenta: publicações periódicas, coleções e editoriais}

Federico Gerhardt ${ }^{1}$

Resumo $\mathrm{O}$ artigo investiga os projetos editoriais promovidos durante os anos 40 por um grupo de exilados galegos em Buenos Aires devido à Guerra Civil Espanhola, na chamada "idade de ouro" da indústria editorial argentina. Este grupo tem como figuras visíveis Rafael Dieste, Luis Seoane e Lorenzo Varela Arturo Cuadrado. A investigação centra-se, por um lado, na publicação de catálogos e coleções criadas ou dirigidas pelos exilados galegos no período: Biblioteca Billiken, Colección Oro, coleções Hórreo, Dorna e Buen Aire, e editorial Nova. Por outro lado, concentra-se em revistas literárias publicadas simultaneamente pelos mesmos exilados: De Mar a Mar, Correo Literario e Cabalgata. Palavras-chave exílio espanhol na Argentina; história editorial; revistas literárias e culturais.

Abstract The article analyzes the editorial projects promoted during the 40s by a group of Galician exiles in Buenos Aires a result of the Spanish Civil War, in the so called "golden age" of Argentina's publishing industry. The visible figures of the group are Rafael Dieste, Luis Seoane, Arturo Cuadrado and Lorenzo Varela.

The investigation focuses on the one hand, in the catalogs of the publishing houses and collections established or directed by the Galician exiles in the period: Biblioteca Billiken, Colección Oro, Hórreo, Dorna, Buen Aire and Nova. On the other hand, examines the literary magazines published simultaneously by the same exiles: De Mar a Mar, Correo Literario and Cabalgata.

\footnotetext{
${ }^{1}$ Doctor en Letras por la Universidad Nacional de La Plata (Argentina). Profesor de la cátedra de Literatura Española II (Facultad de Humanidades y Ciencias de la Educación de la UNLP). Investigador del Consejo Nacional de Investigaciones Científicas y Técnicas (Argentina), desarrollando actualmente el proyecto de investigación "Literatura, crítica literaria y mercado editorial en tres revistas del exilio español en Buenos Aires: De Mar a Mar (1942-1943), Correo Literario (1943-1945) y Cabalgata (1946-1948)", en el Centro de Estudios de Teoría y Crítica Literaria-Instituto de Investigaciones en Humanidades y Ciencias Sociales (UNLP-CONICET). Home page: http://www.conicet.gov.ar/new_scp/ detalle.php?id=37184\&datos_academicos=yes. E-mail: fedegerhardt@hotmail.com
}

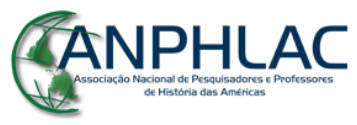

Revista Eletrônica da ANPHLAC, ISSN 1679-1061, №. 19, p. 72-103, jul./dez., 2015. http://revista.anphlac.org.br 
Keywords Spanish exile in Argentina; publishing history; literary and cultural magazines.

\section{Artigo recebido em: 01/08/2015 \\ Artigo aceito para publicação em: 02/12/2015}

El conjunto de exiliados de la Guerra Civil española que arribó a la Argentina presenta como particularidad, en su relativamente reducido número, la importante proporción de artistas e intelectuales en su composición, como consecuencia, en parte, de las gestiones de instituciones culturales y educativas locales (SCHWARZSTEIN, 2001, p. 80-101; MACCIUCI, 2011, p. 159). Dentro de este conjunto tuvo un papel destacado, por su participación en el campo de la producción cultural en la Argentina, un grupo de escritores y artistas de ascendencia gallega, nucleados en torno a las figuras de Luis Seoane, Lorenzo Varela, Arturo Cuadrado y Rafael Dieste.

Más allá de que, en ocasiones, las firmas de los exiliados españoles tuvieron cabida en algunos de los espacios más prestigiosos del campo cultural argentino de la época, tales los suplementos de los grandes diarios como La Nación y La Prensa, y destacadas revistas como Nosotros y Sur (ZULETA, 1991; MARTÍNEZ, 2007), el grupo de gallegos antes mencionado emprendió en Buenos Aires, fundamentalmente en la década del ’40, una intensa labor editorial a través de la fundación de sellos, la dirección de colecciones y la publicación periódica de revistas literarias y culturales, en un momento particularmente propicio de la historia argentina, dentro del periodo del "auge de la industria cultural” (RIVERA, 1998, p. 94) y, más específicamente, en los inicios de la conocida como "época de oro de la industria editorial" (DE DIEGO, 2006, p. 91), que se suele ubicar entre los años 1938 y 1955 , aproximadamente. $^{2}$

\footnotetext{
${ }^{2} \mathrm{Si}$ bien no es el objetivo específico del presente trabajo, centrado en el caso particular de los proyectos editoriales promovidos por los exiliados gallegos en Buenos Aires durante la década del '40, sí resulta pertinente presentar algunos datos que ilustran las proporciones de esta "época de oro" de la industria editorial en tanto contexto en que se desarrollan dichos proyectos. De acuerdo con las cifras calculadas por el Registro Nacional de la Propiedad Intelectual y por la Cámara Argentina del Libro, citadas por Rivera (1998, p. 95-96), el total de obras registradas entre 1900 y 1935 es de 2350, mientras que para el periodo 1936-1939 pasa a ser de 5536. En estos tres años, el total de ejemplares editados asciende a 21.990.000, con tirajes anuales promedio que oscilan entre los 3500 y los 4300 . Entre 1939 y 1940 se produce un cambio en el total de ejemplares impresos, pasando de 9.300 .000 a 12.300.000, el número de obras registradas salta de 2160 a 2671, y el tiraje de 4300 a 4600 . En los cinco años siguientes, sigue el crecimiento de la industria editorial argentina, con un tiraje promedio para el periodo de 5620 ejemplares: 13.300 .000 ejemplares en $1941,20.700 .000$ en $1942,28.400 .000$ en $1943,30.700 .000$ en 1944 y 30.600.000 en 1945. Entre 1946 y
}

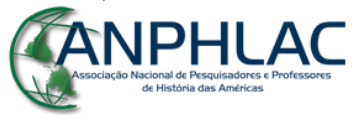

Revista Eletrônica da ANPHLAC, ISSN 1679-1061, №. 19, p. 72-103, jul./dez., 2015. http://revista.anphlac.org.br 
Se trata de una coyuntura favorable por el crecimiento del mercado del libro en la Argentina y por la caída de la industria editorial española como consecuencia de la Guerra Civil y la inmediata posguerra, que permitió no sólo que el libro argentino dominara el mercado interno sino también la expansión de las editoriales argentinas hacia el mercado externo (DE DIEGO, 2006, p. 103-105). Es en este periodo cuando se afianzan y desarrollan empresas editoriales comandadas, en muchos casos, por españoles residentes en Argentina, tales los casos de Sudamericana, por Antonio López Llausás, Emecé, por Mariano Medina del Río y Álvaro de las Casas, y Losada, por Gonzalo Losada (POCHAT, 1991).

Asimismo, otra circunstancia favorable estaba dada por el importante desarrollo de las entidades asociativas de ámbito gallego en Buenos Aires, determinado por las dimensiones de la inmigración gallega en las dos últimas décadas del siglo XIX y, especialmente, las dos primeras del siglo XX (RODINO LALÍN, 1991, p. 290). En este sentido, cabe señalar que las asociaciones étnicas gallegas sumaban a sus funciones asistenciales, una dinámica labor cultural que cobra nuevo impulso hacia fines de la década del '30 con la llegada de los exiliados, vehiculizada por una intensa labor editorial (RODINO LALÍN, 1989), con el objetivo primordial de difundir la cultura galaica y promover la comunicación entre los gallegos y de éstos con la sociedad receptora. ${ }^{3} \mathrm{~A}$ su vez, coincidían en este empeño otros intentos editoriales, ya no institucionales sino particulares, muchas veces impulsados por los mismos agentes. ${ }^{4}$

En el contexto antes brevemente descripto, las redes de solidaridad entre exiliados y las conexiones del mercado editorial muchas veces conjugadas dieron lugar a proyectos editoriales de diversa índole y diferente fortuna en la Buenos Aires de los años '40.

1950, el proceso de crecimiento continúa, no sin fluctuaciones, arrojando un total de 145.800.000 ejemplares editados durante el quinquenio -más de 22.100 .000 por encima del total editado en el tramo 1941-1945-, y con un tiraje promedio de 6940 ejemplares. Para más datos pueden también consultarse los trabajos de Bottaro (1964), Borello (1977) y Getino (1995).

${ }^{3}$ A propósito, sostiene Graciana Vázquez Villanueva: “es necesario considerar que, según las estadísticas, entre 1939 y 1950 emigran 630.000 gallegos de los que el 37\% llegan a Argentina y de los cuales sólo un $6 \%$ ha alcanzado el nivel de educación superior" (2007, p. 3).

${ }^{4}$ A modo de ejemplo, puede remitirse al caso de Luis Seoane, en cuya trayectoria editorial se observa la participación en proyectos de uno y otro tipo, procurando a veces conjugarlos, como en su inédito proyecto para un convenio entre la Editorial Losada y el Centro Gallego de Buenos Aires, para la creación de una "Biblioteca de Escritores Gallegos", fechable en 1939 y recientemente sacado a la luz (GERHARDT, 2015).

\section{GANPHLAC}

Revista Eletrônica da ANPHLAC, ISSN 1679-1061, №. 19, p. 72-103, jul./dez., 2015. http://revista.anphlac.org.br 


\section{Editoriales y colecciones}

\section{Rafael Dieste, director de colecciones divulgativas de la Editorial Atlántida}

Tras haber hecho algunos trabajos de traducción para Sudamericana ${ }^{5}$, en enero de 1940, cuando había transcurrido menos de medio año de su llegada a Buenos Aires, Rafael Dieste se incorpora a la Editorial Atlántida, la empresa fundada en 1917 y dirigida por el uruguayo residente en la Argentina Constancio C. Vigil. El escritor gallego y su esposa, Carmen Muñoz, entran por mediación de la artista plástica, también exiliada, Maruja Mallo, quien por entonces ilustraba numerosas publicaciones del sello (PÉREZ RODRÍGUEZ, 2013a, p. 76; REI NÚÑEZ, 1987, p. 110). Desde entonces, y hasta 1947, Dieste trabajará para Atlántida, llegando a ocupar el cargo de Director Literario del Departamento Editorial. Durante su desempeño en dicho cargo, Rafael Dieste dirigió además dos de las series más emblemáticas de la editorial: la 'Biblioteca Billiken’ y la 'Colección Oro'.

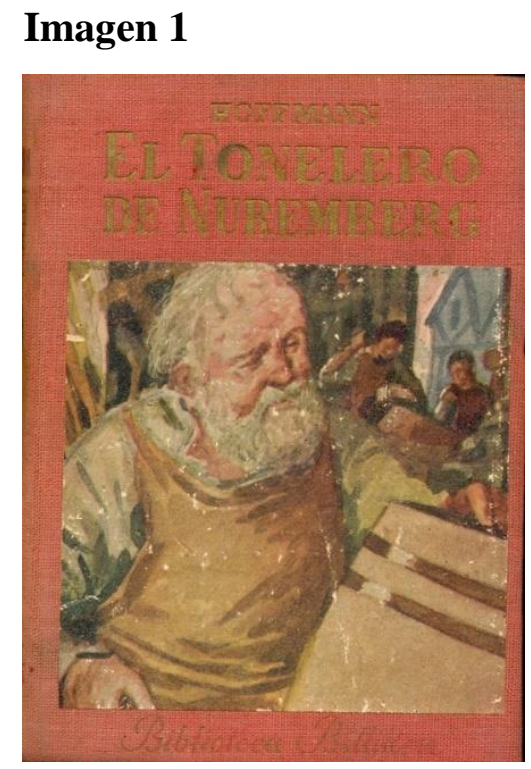

Fonte: El tonelero de Nüremberg

\footnotetext{
${ }^{5}$ Ya en 1939 ve la luz su traducción de Terre des hommes de Antoine de Saint-Exupéry. Cabe presumir que el temprano vínculo con Sudamericana habría estado dado por la relación de Dieste con escritores ligados a la revista Sur, y en particular con Oliverio Girondo, miembro del grupo fundador de aquella editorial, quien organiza una recepción para el escritor gallego a escasos días de su llegada a la Argentina. En carta a Enrique Dieste del 21 de julio de 1939, Rafael anota: "Girondo, Langhe y sus amigos nos dieron un banquete (...) El Secretario de Sur espera mi visita para hablar conmigo de una posible sección que se me encomendaría si llegamos a un acuerdo" (1995, p. 152). En el banquete también participaron, además, otros escritores como, por ejemplo, José González Carbalho, Pablo Rojas Paz y Cayetano Córdova Iturburu (REI NÚÑEZ, 1987, p. 109).
}

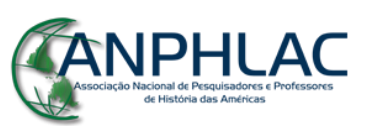

Revista Eletrônica da ANPHLAC, ISSN 1679-1061, №. 19, p. 72-103, jul./dez., 2015. http://revista.anphlac.org.br 
La 'Biblioteca Billiken' estaba compuesta por ediciones, en pequeño formato e ilustradas, de literatura clásica y de biografías de personajes célebres, en versiones y adaptaciones para niños. En ella tuvieron un papel destacado los exiliados españoles, tanto en la función de ilustradores, entre los que cabe mencionar a Luis Seoane, Manuel Colmeiro, Gori Muñoz, y Ramón Pontones; como en la de adaptadores de clásicos, empezando por el propio Dieste, a cuya pluma se deben las versiones de El Conde Lucanor (ilustrado por el también exiliado gallego Castelao), Los cuentos de Tólstoi, El tonelero de Nüremberg, Tartarín de Tarascón, Viajes de Gulliver, y Cuentos de Oscar Wilde. A la suya se sumaron firmas como las de Arturo Serrano-Plaja, Francisco Ayala, Clemente Cimorra y José Otero Espasandín. Éste último, precisamente, recoge años después en libro una anécdota, en la que hace referencia a las cartas recibidas en la redacción de la Editorial Atlántida, y especialmente en una remitida por un joven que se queja "de la avalancha de escritores extranjeros que aparecían en los catálogos de los libros publicados en el país" (citado en: PELEGRÍN, 2008, p. 22). ${ }^{6}$

Más allá de su matiz xenófobo, la queja del anónimo corresponsal pone el foco en la importante presencia de autores españoles exiliados en el catálogo de la 'Biblioteca Billiken', característica que comparte con la 'Colección Oro', la cual, en cierto contexto de bonanza económica en el seno de una editorial de alcance masivo se convirtió en un escenario apto para el ejercicio de la solidaridad por parte de Rafael Dieste, con otros exiliados en la Argentina o allende sus fronteras.

Es así que en el epistolario de Dieste pueden encontrarse sobradas muestras de las diversas gestiones realizadas por el escritor gallego para prestar ayuda a sus compañeros de infortunio, generalmente relacionadas con sus conexiones en la industria editorial. Por ejemplo, referencias a las gestiones realizadas para permitir la entrada a la Argentina de dos ex compañeros de Dieste en las Misiones Pedagógicas antes de la Guerra Civil española, José Otero Espasandín y Arturo Serrano Plaja, en las que apela además a la intervención directa de Constancio Vigil y de Gonzalo Losada, respectivamente (DIESTE, 1995, p. 166, 174). Y, más específicamente, las cartas de Dieste dan cuenta de

\footnotetext{
${ }^{6}$ En el mismo texto, comienza caracterizando a la 'Biblioteca Billiken': "Hace muchos años, muchos. En Buenos Aires, calle Florida. En el primer piso, mirando a la calle, una gran mesa donde Carmen y Rafael Dieste trataban de poner a derechas, en lo posible, una colección de libros muy difícil de describir. Según le habían dicho a Dieste, aquello se proponía ser 'la invención de literatura para niños entre los siete y los ochenta años" (PELEGRÍN, 2008, p. 22).
}

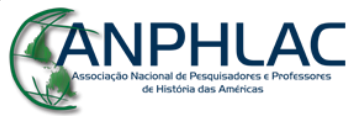

Revista Eletrônica da ANPHLAC, ISSN 1679-1061, №. 19, p. 72-103, jul./dez., 2015. http://revista.anphlac.org.br 
las propuestas que dirige a otros exiliados españoles, en las que subyace la ayuda económica en la difícil situación. Pueden mencionarse, sólo a título de ejemplo, las misivas dirigidas a españoles exiliados en México, como María Zambrano, Luis Santullano y Antonio Sánchez Barbudo, todos ellos también de activa participación en las Misiones Pedagógicas. En un pasaje que, con variaciones, se repite en otras cartas con el mismo asunto, la dirigida a Sánchez Barbudo el 14 de febrero de 1943 presenta una reseña ilustrativa de diferentes aspectos de la serie:

\begin{abstract}
Voy a intentar una brevísima historia (¡horror! No la intento). Quedamos en que encomiendo a tu imaginación lo principal de mi descargo, y lo demás a tu tolerancia, y salto sin más a los negocios. ¿Quieres hacer un pequeño libro titulado Magos, astrólogos y alquimistas? Hermoso asunto. Podemos pagarte (Editorial Atlántida) trescientos pesos argentinos. A Lorenzo le encargué El Renacimiento. A Plaja, Los místicos. A Salas, una breve Teoría de la música. Si continúa esta buena racha de mis atribuciones acaso podré encargarte alguna otra cosa. Vamos a ver. Toma nota de los detalles o pon una señal donde haya riesgo de olvido.

Extensión: Alrededor de setenta y cinco pliegos de máquina a doble espacio, o sea a razón de unas treinta líneas por pliego. Si necesitaras alargar el asunto en diez cuartillas más, puedes hacerlo. En todo caso, la retribución es la misma. Carácter del libro: debe ser claro, ordenado, ameno, distribuido en capítulos. Debe tener valor didáctico pero no aire académico. Llaneza, pero elegancia, etc. Debe poder ser entendido por cualquier muchacho a punto de salir de la escuela y que no sea un zoquete, y por sus padres, si no son también unos zoquetes. En suma, un libro de divulgación que no exija para ser entendido conocimientos especiales ni más hábito literario que el de leer una revista no literaria. Sin embargo, el libro debe ser bonito, noble, como una buena conferencia de Misiones que pudiera escuchar con gusto cualquiera de los misioneros además del público. (DIESTE, 1995, p. 185)
\end{abstract}

Esta última referencia a las Misiones Pedagógicas, en las que intervinieron activamente los intelectuales antes citados, se da en consonancia con el carácter divulgativo de la 'Colección Oro', la cual abarcaba las temáticas más diversas, tal como se observa en los nombres de las secciones que la componían: 'Artes y letras', 'Temas Científicos y Geográficos', 'Temas Históricos', 'Derecho y Sociología', 'Filosofía' y 'Temas Varios'?

\footnotetext{
${ }^{7}$ Tal como señala Pelegrín (2008, p. 16-23), esta relación con las Misiones Pedagógicas puede extenderse al catálogo de la 'Biblioteca Billiken', en otro aspecto que comparten ambas colecciones editadas por Atlántida y dirigidas por Dieste.
}

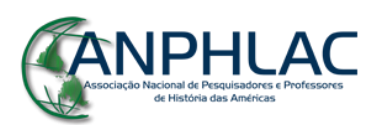

Revista Eletrônica da ANPHLAC, ISSN 1679-1061, №. 19, p. 72-103, jul./dez., 2015. http://revista.anphlac.org.br 


\section{Imagen 2}

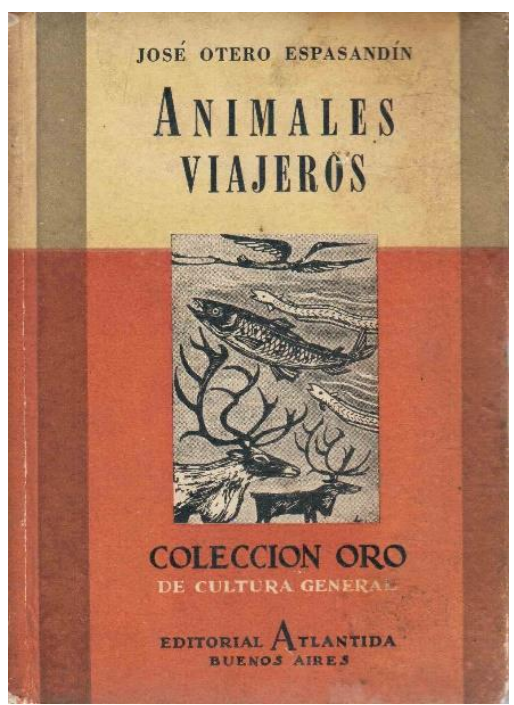

Fonte: Animales viajeros

Tal como señalaba aquella queja epistolar recordada por José Otero Espasandín, entre las firmas que componen el catálogo de la colección pueden encontrarse un número considerable de exiliados españoles, muchos de ellos con más de un título. El caso más extremo lo constituye el propio Otero Espasandín, a quien corresponden las primeras catorce entregas de la colección, y que en total suma más de veinte títulos variados, entre los que se incluyen Animales viajeros, Volcanes y terremotos (con el pseudónimo de Roger Moulin), La Grecia heroica y clásica, Pobladores del mar, Prodigios de las aves, El cortejo solar, Un paseo por el cielo, Sociedades de insectos, etc. A él se suman el propio Rafael Dieste (Nuevo tratado del paralelismo), Francisco Ayala (Historia de la libertad), Clemente Cimorra (Historia del periodismo, Rockefeller y su tiempo, Prosas maestras castellanas), Javier Farías (Literatura italiana, Historia del teatro), Lorenzo Varela (El Renacimiento), entre otros.

No obstante esta presencia de los exiliados, en la 'Colección Oro' tendrán cabida las firmas de autores argentinos, en muchos casos relacionados con Dieste y otros proyectos editoriales en los que formó parte, tales los casos de Luis Baudizzone (Cervantes), Jorge D’Urbano (Cómo escuchar un concierto), Cayetano Córdova Iturburu (Cómo ver un cuadro, La pintura argentina del siglo XX), Pablo Rojas Paz (Biografía de Buenos Aires, Los hombres y momentos de la diplomacia).

Durante los años en que Rafael Dieste formó parte de la Editorial Atlántida, la$$
\text { GANPHLAC }
$$

Revista Eletrônica da ANPHLAC, ISSN 1679-1061, №. 19, p. 72-103, jul./dez., 2015.

http://revista.anphlac.org.br 
'Colección Oro' continuó su crecimiento hasta superar ampliamente el centenar de volúmenes, sin embargo, a principios de 1948, la empresa editorial entra en un periodo de dificultades que acaban determinando la salida de Rafael Dieste, junto a Carmen Muñoz, según explica aquél en carta a Antonio Dieste del 28 de septiembre de ese mismo año: "Hace varios meses que Carmen y yo dejamos Atlántida por propia iniciativa, al convencernos de que la crisis editorial alejaba indefinidamente la esperanza de mejorar nuestra situación en la empresa" (DIESTE, 1995, p. 279). De este modo, ponía fin a la tarea emprendida en 1940. Precisamente en ese mismo año, otros dos exiliados gallegos, ligados al propio Dieste se embarcaban en la dirección de colecciones para otra editorial porteña.

\section{Cuadrado y Seoane, de Galicia al Río de la Plata: 'Hórreo', 'Dorna' y 'Buen Aire'}

En el año 1939 se inicia la editorial Emecé, promovida por Mariano Medina del Río y Álvaro de las Casas, dos gallegos residentes en Buenos Aires, y financiada por la familia Braun Menéndez. Álvaro de las Casas habría sido el impulsor de la línea galleguista de la editorial (DEVOTO, 2012, p. 170), cuyos dos primeros libros formaron parte de la "Biblioteca Gallega", que reunía obras relacionadas con la cultura galaica en gallego o castellano. Al año siguiente, en 1940, se produce la entrada de Luis Seoane y Arturo Cuadrado a Emecé,

El poeta Arturo Cuadrado, ex director de la revista Resol (1932-1936), acababa de llegar, en noviembre de 1939 a Buenos Aires, a bordo del Massilia, junto a otros refugiados como el pintor y escenógrafo Gori Muñoz, el escritor y periodista Clemente Cimorra y el pintor Ramón Pontones (SCHWARZSTEIN, 1997, p. 423-424). Por su parte, el escritor y artista plástico Luis Seoane ya había empezado a desarrollar su labor editorial de este lado del Atlántico desde 1938, año en que comienza a hacer trabajos para una de las grandes casas editoras de la Argentina, la Editorial Losada, fundada en agosto. ${ }^{8}$

En Emecé, Seoane y Cuadrado compartirán staff editorial con otros gallegos como Manuel Colmeiro, Eduardo Blanco-Amor y Rafael Dieste. Seoane y Cuadrado se desempeñarán en diferentes tareas, desde la lectura previa y selección de obras, el trabajo

\footnotetext{
${ }^{8}$ En ese mismo año, además, entra a trabajar en el Centro Gallego de Buenos Aires, quedando a cargo de la publicación periódica Galicia, órgano de difusión de la institución.
}

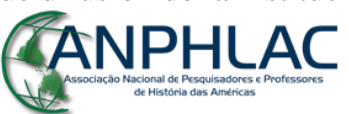

Revista Eletrônica da ANPHLAC, ISSN 1679-1061, №. 19, p. 72-103, jul./dez., 2015. http://revista.anphlac.org.br 
directo con la imprenta, la corrección de pruebas, e incluso la distribución (PÉREZ RODRÍGUEZ, 2007, p. 36). Además, el propio Seoane se encarga de cuidar el diseño y la diagramación de los libros hasta 1942, y las ilustraciones de algunos de ellos, aunque no siempre aparezca este trabajo reflejado en los créditos del mismo (PÉREZ RODRÍGUEZ, 2007; 2009).

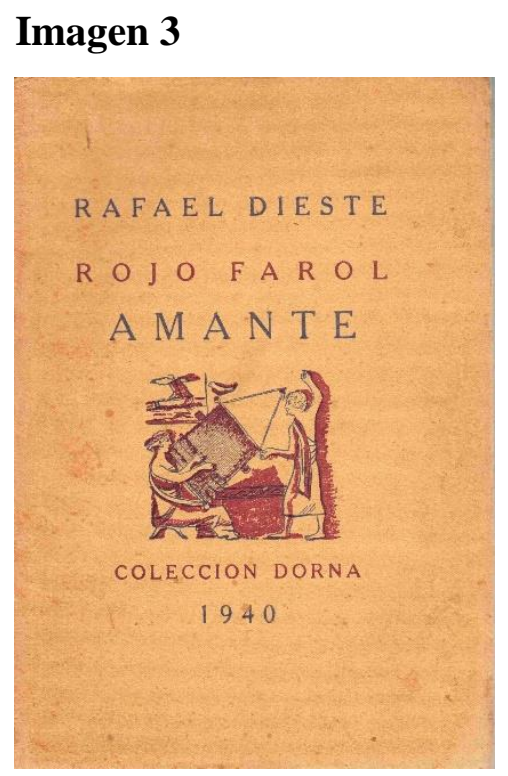

Fonte: Rojo faro amante, 1940

Particularmente, la tarea más notable y más destacada por los estudios posteriores, desarrollada por Seoane y Cuadrado dentro de Emecé fue llevar adelante las colecciones 'Dorna' y 'Hórreo', ambas de temas y autores gallegos. De Seoane son, asimismo, las marcas tipográficas de cada colección, y también las ilustraciones de tapa e interiores de la mayoría de los volúmenes. En el marco de la colección 'Dorna', destinada a la poesía, aparecieron obras como Rojo farol amante (1940) de Rafael Dieste, Queixumes dos pinos (1940) de Eduardo Pondal, Cantigas de Macías o namorado (1941), y el Cancionero popular gallego (1942) de José Pérez Ballesteros.

Los títulos reunidos en la colección 'Hórreo', por su parte, presentaban una mayor variedad genérica, que incluye novelas, cuentos breves, leyendas populares y$$
\text { GANPHLAC }
$$

Revista Eletrônica da ANPHLAC, ISSN 1679-1061, №. 19, p. 72-103, jul./dez., 2015. http://revista.anphlac.org.br 
fundamentalmente ensayo histórico y filosófico, sobre todo pero no exclusivamente, de autores de los siglos XVIII y XIX, como Concepción Arenal, Rosalía de Castro, Emilia Pardo Bazán, Fray Martín Sarmiento, entre otros. A su vez, dentro de la misma colección, la llamada "Serie Blanca" guardaba lugar para los escritores españoles no gallegos, y en ella se publicaron El señor de Bembibre de Gil y Carrasco y Los sueños de Francisco de Quevedo.

Asimismo, dentro de la misma editorial Seoane y Cuadrado, en colaboración con Luis Baudizzone ${ }^{9}$ - años más tarde, fundador y director de la Editorial Argos -, fundaron y desarrollaron, también en Emecé, la Colección 'Buen Aire', cuyo subtítulo aclaraba "Imágenes y espíritu de América". Se trataba, entonces, de un proyecto editorial diferente de 'Hórreo' y 'Dorna', en este caso ya no enfocado en la cultura gallega sino mirando a la cultura del país y el continente receptores. ${ }^{10}$

En el catálogo de 'Buen Aire’ durante la participación en el proyecto de Seoane y Cuadrado puede advertirse una considerable variedad de géneros que abarcan desde crónicas y libros de viaje hasta biografías y documentos, pasando por poesía, teatro, cuentos, leyendas y demás, todos ellos con un denominador común: su relación con la cultura americana, fundamentalmente argentina y rioplatense, aunque también guardando un lugar a la brasileña. La colección se inicia en 1941 con Buenos Aires visto por los viajeros ingleses, a la que siguen ese mismo año Cancionero del tiempo de Rosas (selección de José Luis Lanuza), y Las Pampas, que incluye textos de José Hernández y otros autores argentinos. $\mathrm{Al}$ año siguiente toma impulso y publica numerosos volúmenes, entre los que se cuentan, por ejemplo, dos libros cuya edición estará al cuidado de Baudizzone, Cuadrado y Seoane: Lira romántica suramericana y Alôs Afro-Brasileños, del diplomático brasileño Newton Freitas.

\footnotetext{
${ }^{9}$ Y con José Luis Lanuza, según Pochat (1991).

${ }^{10}$ En una entrevista posterior, declara Seoane: "Nosotros comenzamos en Emecé con una colección que se llamaba 'Buen Aire', porque sólo el afán nuestro[,] de Cuadrado, Baudizzone y yo, que comenzamos los tres haciendo 'Buen Aire', era el de hacer una pequeña colección de libros que fuesen muy bonitos, pero al mismo tiempo fuesen el reflejo de lo que era Latinoamérica. (SEOANE, 2009, p. 167). En otra sección de la entrevista, Seoane, aunque sin mencionar a Cuadrado, insiste en la idea: "Yo fui amigo de Baudizzone, con quien hice una colección de libros, 'Buen Aire'” (2009, p. 172).
}

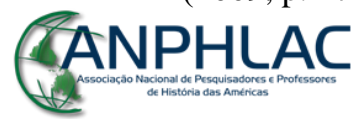

Revista Eletrônica da ANPHLAC, ISSN 1679-1061, №. 19, p. 72-103, jul./dez., 2015. http://revista.anphlac.org.br 


\section{Imagen 4}

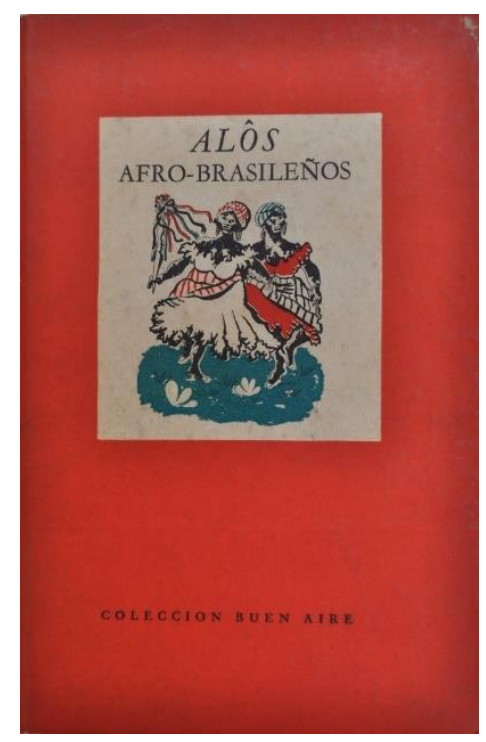

Fonte: Alôs Afro-Brasileños

Este movimiento de apertura, desde las colecciones galleguistas a la colección 'Buen Aire', que toma como objeto la cultura americana, es saludado, también en el exilio, por María Teresa León el 21 de febrero de 1942, en el artículo "Una editorial y su elogio", a propósito de Emecé, publicado en España Republicana, periódico del Centro Republicano Español en Buenos Aires, como una iniciativa tendiente a estrechar lazos con la cultura receptora del exilio español, afirmando, en el citado elogio, que la misma "sirve de felicísimo emparejamiento de los trabajos de los escritores españoles en destierro con los que tan generosamente les hicieran lugar" ". La colección 'Buen Aire' continuará su andadura incluso una vez producida la salida, por motivos no del todo esclarecidos $^{12}$, de Cuadrado y Seoane en 1942.

\footnotetext{
${ }^{11}$ En la misma nota, señala: "Comenzaron desentrañando la cultura gallega. Si tenemos en cuenta que una enorme masa emigrante de la costa de Galicia guarda su idioma de niñez entre cuatro recuerdos iniciales que cimentan la vida de todo hombre, era un acierto ofrecerles clasificada y en orden de buen gusto la literatura de aquella región de España [...] No sé hasta qué punto se han dado cuenta los gallegos que viven apresados en redes más inmediatas de afán, pero si un regalo pudieron depositar con orgullo en la cuna de su hijo, ya argentino, es esta colección de libros. [...] Pero he de añadir que las ediciones Emecé no se han detenido en el mundo cerrado de la literatura vernácula de los gallegos. [...] Han ensanchado su campo y han iniciado una colección sobre temas argentinos".

${ }^{12}$ En relación con la causa probable de la salida de Cuadrado y Seoane de Emecé, tres son las versiones que circulan: que se negaron a editar un libro del entonces embajador de la España franquista en la Argentina, que hicieron lo propio con una novela de Camilo José Cela, y que se solidarizaron con Lorenzo Varela ante los ataques recibidos por su militancia comunista. Señala Pérez Rodríguez, tras repasar estos tres motivos probables, que a ellos "se une que eran escasas las ventas de las obras de nuestros escritores o sobre nuestra Tierra, por lo que los resultados económicos tampoco jugaban a su favor" (2009, p. 112). En
}

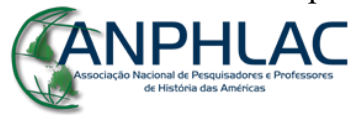

Revista Eletrônica da ANPHLAC, ISSN 1679-1061, №. 19, p. 72-103, jul./dez., 2015. http://revista.anphlac.org.br 


\section{La continuidad en un nuevo proyecto: la Editorial Nova}

Tras su salida de Emecé, Seoane y Cuadrado fundan en diciembre de 1942 la Editorial Nova, sello del que es parte también la Imprenta López con el 50\%, mientras que la mitad restante se reparte en partes iguales entre los mencionados editores gallegos ${ }^{13}$. Es precisamente en esos talleres en los que van a imprimirse todos los volúmenes de la editorial en el periodo abordado, volúmenes cuyo diseño, en todos sus aspectos, estará a cargo de Luis Seoane (PÉREZ RODRÍGUEZ, 2013b, p. 120).

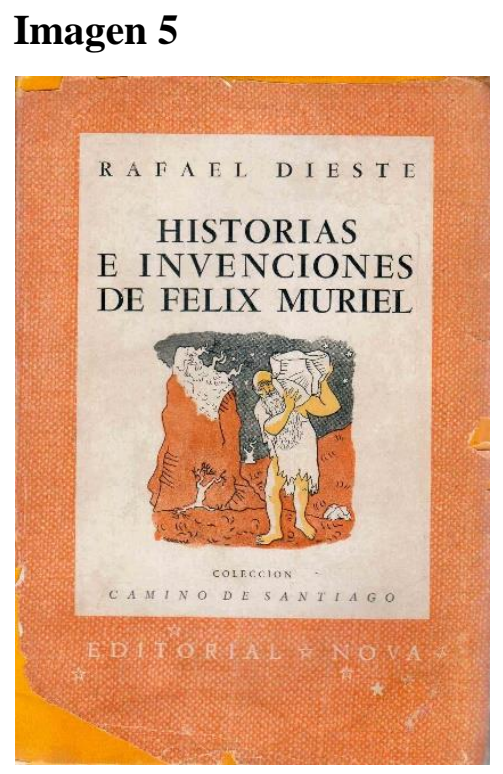

Fonte: Historias e invenciones de Félix Muriel

El catálogo que Nova va construyendo en el transcurso de los seis años en que la dirigen Luis Seoane y Arturo Cuadrado presenta ciertas continuidades con las iniciativas desarrolladas en el seno de Emecé. Es así que una de sus colecciones más emblemáticas sea 'Camino de Santiago', dedicada una vez más a la cultura gallega. La misma cuenta

igual sentido apunta De Diego, quien agrega ciertos detalles a esta hipótesis: "Parece ser, incluso, que la deserción de los dos gallegos de Emecé tuvo que ver con el giro de la editorial hacia la publicación de autores argentinos como Mallea y Borges, política a la que ellos se mostraban reticentes, ya que preferían continuar con la edición de textos de temática galleguista muy poco rentables" (2006, p. 99). En 1942, en la sección "Mercado de las artes y las letras", de Galicia, los dos editores gallegos publican una nota dando su versión de los hechos: "razones de orden administrativo y de orden político que incitaban a una deslealtad a Galicia y a España, crearon una incompatibilidad moral justificativa de la escisión que hoy hacemos pública".

13 Agradezco este dato a Xosé Luís Axeitos, que ha consultado la documentación económica correspondiente.

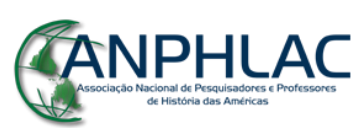

Revista Eletrônica da ANPHLAC, ISSN 1679-1061, №. 19, p. 72-103, jul./dez., 2015.

http://revista.anphlac.org.br 
con once títulos, y se abre con Historias e invenciones de Félix Muriel, de Rafael Dieste ${ }^{14}$. Las restantes entregas presentan textos de temas y/o autores gallegos (clásicos y contemporáneos), en su mayoría en idioma castellano, incluyendo títulos como Cuadros de la guerra de Concepción Arenal (1942) o Adolescencia de Ramón Otero Pedrayo (1944). Cabe destacar, en relación con 'Camino de Santiago', que su finalización se da de manera anticipada, en 1945, en lo que podría presumirse nuevamente como el resultado de escasos réditos económicos de una empresa enfocada en la difusión de la cultura gallega. Lo propio podría pensarse también de 'Pomba', la colección dedicada a la poesía y dirigida por Arturo Cuadrado, que contó con un solo volumen, Torres de amor de Lorenzo Varela (1942), antes de ser rebautizada y castellanizada como 'Paloma', para reorientar la conformación de su catálogo. A propósito, en carta a Fernández del Riego, del 6 de julio de 1951, Luis Seoane afirma:

\begin{abstract}
Los únicos "mecenas" conocidos por mí en cuanto a problemas culturales gallegos, perdóname, somos Cuadrado y yo, que publicamos como hemos podido más de cincuenta libros gallegos en las colecciones 'Hórreo', 'Dorna', 'Camino de Santiago' y 'Pomba', aunque a mí me quede mal decirlo y perdiendo en esta labor lo mejor de nuestros años pues lo hicimos no sólo sin beneficio sino incluso sacando el dinero de otros trabajos para hacerlo.
\end{abstract}

Pero en Nova, la continuidad con respecto al proyecto editorial de Emecé no se reduce a las colecciones de temática o autores gallegos de escasa fortuna, sino que además está relacionada con la presencia de colecciones vinculadas con la cultura americana. En este aspecto del catálogo, se destaca la colección 'Mar Dulce'. ${ }^{15}$

Dirigida por Luis Baudizzone, la colección publicó una veintena de libros, y en su catálogo se conjugan textos diversos relacionados con la historia americana,

\footnotetext{
${ }^{14}$ En carta a Antonio Sánchez Barbudo de junio de 1943, Rafael Dieste le escribe el siguiente párrafo, que ilustra claramente los cruces entre las conexiones editoriales y las redes de solidaridad entre exiliados españoles: "Ahora debo decirte, aunque acaso ya te lo haya dicho Varela, que tu libro [podría referirse a Sueños de grandeza; v. infra] va a ser compañero del mío, no sé si en la misma colección o en otra no menos bien vestida de la editorial Nova. Estos galaicos editores mundiales deben ser apoyados por todos los amantes de las nuevas letras hispanas. Quiero decir concretamente que si alguno de vosotros (incluyendo en el vosotros a los amigos mejicanos) hace alguna nota sobre el libro mío, o sobre cualquier otro que os interese de la misma editorial, conviene y es justo dedicar a ésta una elegante loa. Bien, prescindo ahora del énfasis y apelo a tu generosa capacidad de simpatía para que no dejes de recomendar esto con calor a quien pueda hacerlo" (DIESTE, 1995, p. 187-188).

${ }^{15}$ Años más tarde, y tal vez extremando su innovación, Seoane la recuerda como "la primera colección americana, posiblemente la primera colección americana que aparecía en ese momento en América" (2009, p. 167). Lo cierto es que, más bien y como se ha dicho antes, la colección parecía continuar con el proyecto de 'Buen Aire'.
}

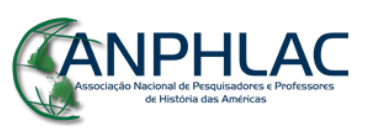

Revista Eletrônica da ANPHLAC, ISSN 1679-1061, №. 19, p. 72-103, jul./dez., 2015. http://revista.anphlac.org.br 
remontándose nuevamente a tiempos precolombinos, dedicando la mayoría de los títulos a la cultura argentina y dando también cabida al Brasil. Entre los volúmenes que componen su catálogo pueden mencionarse, sólo a modo de ejemplo, el Guamán Poma (prologado por Luis Baudizzone) (1943), Amazonia. Leyendas Ñangatú (selección y noticia de Newton Freitas) (1943), Fausto de Estanislao del Campo (con prólogo de Jorge Luis Borges) (1946), y La calavera y otros grabados de Guadalupe Posada (selección de Luis Seoane) (1943).

Al igual que en 'Buen Aire', este repaso pone de relieve el enfoque de la colección 'Mar Dulce' en el pasado americano, dando lugar a material folklórico, tradicional y popular, que incluye aspectos distintivos de las culturas indígenas, de las coloniales de origen hispánico o portugués, y de las criollas. Este panorama, a su vez, se completa con algunos de los títulos incluidos en otras colecciones mucho menos extensas, como 'Nuestra América'16, la 'Biblioteca Americanista' y 'Viajeros de las Américas'. ${ }^{17}$

A cargo de Lorenzo Varela estuvieron la colección 'Páginas Íntimas', la 'Serie Siglo XIX' y la 'Serie Romántica', colecciones breves todas ellas que incluyeron mayormente libros de o sobre autores franceses (por ejemplo, Víctor Hugo y Balzac), mayormente en traducciones del propio Varela o de Arturo Serrano Plaja. Por otra parte, José Luis Romero se encargó de la dirección de la 'Biblioteca Histórica', compuesta por la 'Serie Los Historiadores Ilustres' y la 'Serie Los Estudios Contemporáneos'.

Por último, entre las numerosas colecciones de $\mathrm{Nova}^{18}$, cabe destacar otras dos, por su relevancia en lo que respecta a la relación del sello con el mercado editorial local y a sus vínculos con el campo cultural argentino de la época.

Por un lado, la colección ‘El Espejo del Mundo', en la que ve la luz una sola obra originalmente en castellano, Sueños de grandeza de Antonio Sánchez Barbudo. El resto, y en consonancia con la importancia de las traducciones en el mercado editorial argentino

\footnotetext{
${ }^{16}$ Había sido anunciada como primera entrega de la colección 'Tierra Firme', la cual nunca se publicó tal vez por la coincidencia con el título de la famosa colección americanista que el Fondo de Cultura Económica sacó a la calle en 1944.

${ }^{17}$ En un trabajo leído en marzo del presente año, en el seminario "Editores españoles en Argentina (19381955)" de la Universidad de Alcalá de Henares, titulado "Las literaturas argentina y latinoamericana en los proyectos editoriales de los exiliados gallegos en Buenos Aires en la década del 40", he abordado más extensamente las colecciones americanas de Emecé y, especialmente, Nova.

${ }^{18}$ Un análisis global del catálogo de la Editorial Nova en el periodo de dirección de Cuadrado y Seoane puede encontrarse en el trabajo "Nova 1942-1947: una editorial de exiliados gallegos en Argentina" de María Antonia Pérez Rodríguez (2013b).
}

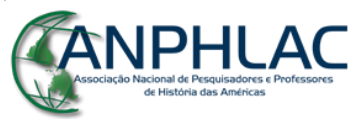

Revista Eletrônica da ANPHLAC, ISSN 1679-1061, №. 19, p. 72-103, jul./dez., 2015. http://revista.anphlac.org.br 
de la época (DE DIEGO, 2006, p. 112), se trata de obras cuyos originales en idioma extranjero son vertidas al castellano, entre las que cabe destacar las traducciones de Memorias de una enana de Walter de la Mare y El hombre que sabía demasiado de Chesterton, por Julio Cortázar, que vieron la luz en 1946.

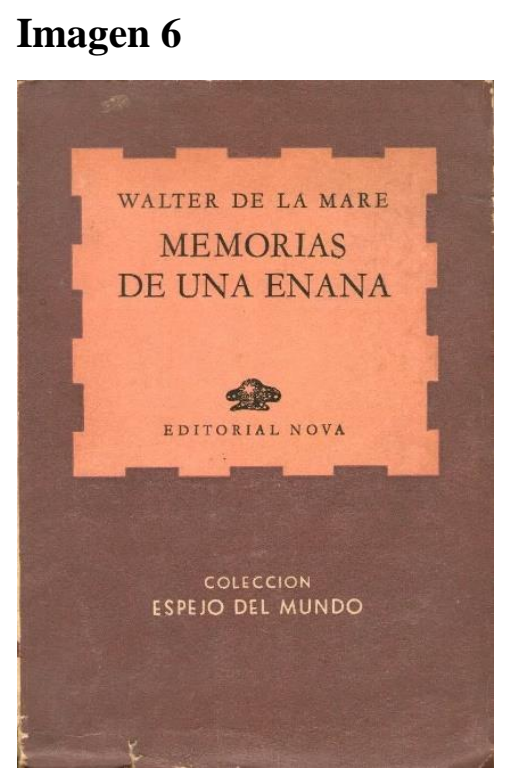

Fonte: Memorias de una enana

Por otro lado, la colección 'Paloma', continuación, con título castellanizado, de 'Pomba'. En ella, y bajo la dirección de Arturo Cuadrado, podría decirse que se produjo lo que Fernando Larraz denomina una "fusión transatlántica" (2011: 140), es decir, la coexistencia dentro de una misma colección de escritores rioplatenses y españoles exiliados. Entre los primeros pueden mencionarse a Cayetano Córdova Iturburu (El viento en la bandera de 1945), Alberto Girri (Playa sola de 1946), Ulyses Petit de Murat (Aprendizaje de la soledad de 1943) y Vicente Barbieri (Anillo de sal de 1946), y las uruguayas Sarah Bollo (Antología lírica de 1948) y Clara Silva (La cabellera oscura de 1945); entre los segundos se encuentran Arturo Serrano Plaja (Versos de guerra y paz de 1945), Jesús Cancio (Maretazos de 1947) y el propio Arturo Cuadrado bajo el seudónimo de Venancio Viera (Los peces turbados de 1945). Asimismo, el aspecto diferencial de esta colección con respecto a las antes mencionadas reside en su carácter contemporáneo, es decir que los títulos no están orientados a rescatar, preservar o difundir un acervo cultural del pasado sino que consisten en la edición de autores que se desenvuelven en el campo literario local de la época.

\section{GANPHLAC}

Revista Eletrônica da ANPHLAC, ISSN 1679-1061, №. 19, p. 72-103, jul./dez., 2015. http://revista.anphlac.org.br 
Hacia fines de 1947 la Editorial Nova irá deteniendo su producción, proceso que se extenderá hasta el año siguiente, cuando en septiembre, en diálogo con Dieste, Lorenzo Varela le confirma que "Nova continúa en pleno letargo" (DIESTE, 1995, p. 276). Como resultado, ese mismo año de 1948 Seoane y Cuadrado abandonan la editorial.

\section{Las revistas literarias como parte del entramado editorial}

\section{De Mar a Mar (1942-1943)}

Simultáneamente a la publicación de las colecciones y los sellos fundados o promovidos por el grupo de gallegos exiliados en Buenos Aires, a los que se ha hecho referencia en las líneas precedentes, se fueron desarrollando otros iniciativas editoriales concebidas por los mismos agentes en la prensa periódica porteña, y que constituyeron una parte fundamental de un proyecto editorial más vasto. El primero de ellos, iniciado en el mismo año en que Seoane y Cuadrado fundan Nova, es De Mar a Mar.

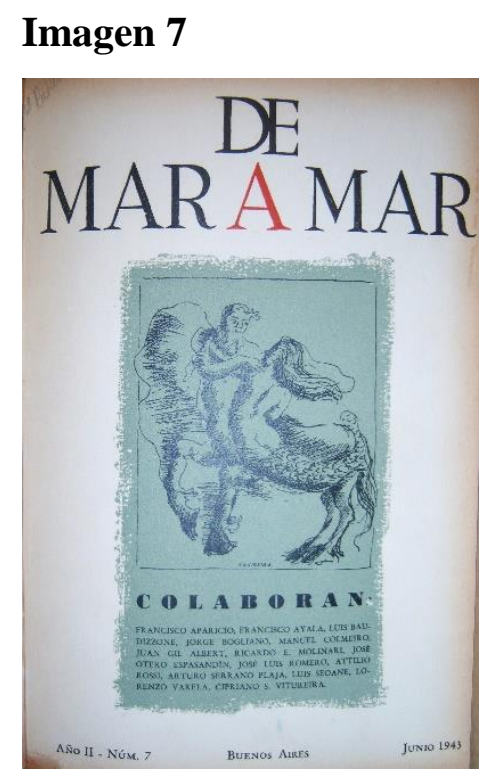

Fonte: De Mar a Mar, junio de 1943

En diciembre de 1942 apareció el primer número de De Mar a Mar, título que en ésta y sus posteriores entregas fue acompañado por la indicación "Revista literaria mensual". En su breve texto de presentación, incluido en el número inicial, el grupo fundador compuesto fundamentalmente por exiliados gallegos, manifiesta la voluntad de 
integrar la publicación en el campo literario local, pretensión que a lo largo de los siguientes seis números se irá realizando por medio de la inclusión de una creciente nómina de colaboradores compuesta no sólo por exiliados sino también por los nombres de escritores y artistas argentinos, y, en menor medida, uruguayos y brasileños. Concluye la presentación de la revista, diciendo: "De Mar a Mar se inicia al calor fraternal de unos cuantos amigos, europeos y americanos, unos en Buenos Aires, otros dispersos por el continente" $\left(\mathrm{n}^{\circ} 1\right.$, p. 6).

A la cabeza del grupo fundador se encontraban, como secretarios, Lorenzo Varela y Arturo Serrano-Plaja ${ }^{19}$. A Varela y Serrano-Plaja se sumaban, dentro del grupo fundador y como colaboradores asiduos, una vez más, Arturo Cuadrado y Luis Seoane. Los números de De Mar a Mar se imprimían en la Imprenta López, la misma en que lo hacían los libros de Nova.

Junto a los nombres que componen el núcleo inicial de la revista se suman los colaboradores cuya lista, en constante crecimiento, se incluye en cada número. La nómina del primer número está compuesta por los siguientes artistas y escritores: Luis Seoane, Arturo Cuadrado, Manuel Colmeiro, José Otero Espasandín, Rafael Alberti, Francisco Ayala, Guillermo de Torre, Ramón Pontones y; los argentinos Enrique Anderson Imbert, Horacio Butler, Eduardo Mallea, Ricardo Molinari, Eduardo Sacriste, el ítaliano Attilio Rossi (autor de la viñeta de tapa del primer número) y el brasileño Newton Freitas. La lista se cierra con un etcétera que se irá completando en los números siguientes con la incorporación de españoles como Antonio Sánchez Barbudo y Alejandro Casona, y de argentinos como José Luis Romero y Luis Baudizzone, entre otros.

La composición de esta nómina podría considerarse como un síntoma de la voluntad de integrar la publicación en el campo literario y cultural local. No obstante, en los textos de crítica literaria $-y$, más específicamente, las noticias bibliográficaspredominan las firmas de los exiliados y, especialmente, de los gallegos. Estos textos de crítica literaria tienen en la revista un lugar aparte que, bajo el título "Libros", ocupaba un espacio importante: entre seis y nueve páginas de las aproximadamente cincuenta que tenía cada número. Las reseñas publicadas en De Mar a Mar estaban a cargo de los

\footnotetext{
${ }^{19}$ Ambos habían coincidido, en su exilio mexicano, en la revista Romance. Asimismo, Lorenzo Varela, también en México, compartió con Antonio Sánchez Barbudo un lugar en Taller. Aún más atrás en el tiempo, en la Península, Varela también había participado de la célebre Hora de España, al igual que otros luego exiliados como el mismo Sánchez-Barbudo y Rafael Dieste (CAUDET, 2007, p. 181-183).
}

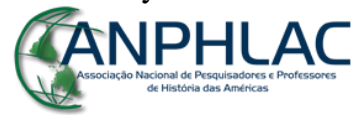

Revista Eletrônica da ANPHLAC, ISSN 1679-1061, №. 19, p. 72-103, jul./dez., 2015. http://revista.anphlac.org.br 
secretarios de la revista, Varela y Serrano-Plaja, y de Otero Espasandín, Cuadrado, Dieste y Farías.

De acuerdo con el objetivo de difundir la obra de los exiliados entre otros desterrados e integrarse en la cultura argentina, la sección bibliográfica otorgó un lugar preponderante a los libros editados en Buenos Aires por los sellos a los que se hallaba ligado el grupo fundador, y, en particular, a las obras de los exiliados. Como contraparte, las citadas editoriales aportaban al sostén económico de la revista mediante la publicidad, generalmente, a página completa, que ocupaba alrededor de cinco páginas en cada número, en folios agregados al principio y al final del mismo. Esta característica de la revista se mantiene desde el primer número hasta el séptimo y último, aparecido en junio de $1943 .^{20}$

\section{Correo Literario (1943-1945)}

En su número 110, de diciembre de 1943, la sección "Revistas" de Sur saluda la aparición de una nueva publicación en Buenos Aires: "Siempre se sintió la necesidad, en los países de habla española, de un periódico semejante a Les Nouvelles Littéraires. Correo Literario tiene el propósito de llenar ese vacío; su presentación y su material son excelentes" ( $\mathrm{n}^{\circ} 110$, p. 113). La noticia se completa con una breve referencia a los contenidos del primer número y un recorrido por algunas de sus firmas, entre las que se menciona a Francisco Ayala, Rafael Alberti, Arturo Serrano Plaja, Cayetano Córdova Iturburu y Romualdo Brughetti. ${ }^{21}$

Precisamente el 15 de noviembre de 1943 comienza su andadura Correo Literario, "Periódico quincenal" que, a partir del número 37 tendrá una frecuencia mensual. La nueva publicación retoma en cierto sentido el proyecto interrumpido de De Mar a Mar 22 .

\footnotetext{
${ }^{20}$ Un análisis más detenido de esta dinámica de relación que atraviesa la construcción de De Mar a Mar, haciendo foco especialmente en el primer número, puede encontrarse en "Entre la prensa y el libro, entre España y la Argentina. Crítica literaria y mercado editorial en la revista De Mar a Mar" (GERHARDT, 2013).

${ }^{21}$ Un detalle curioso: la misma revista Sur también publicó una breve pero elogiosa nota sobre la aparición de De Mar a Mar, a la que saluda como una "nueva revista que agrupa a conocidos escritores, muchos de ellos expatriados" y de la que destaca: "es elogiable la presentación material de la revista" (n 105, p. 114). Lo curioso es que la noticia ve la luz en el número 105 de la revista de Victoria Ocampo, de julio de 1943, es decir, un mes después de la última entrega de De Mar a Mar.

${ }^{22}$ No obstante, no se trataría de un relevo de la publicación anterior, ya que, aunque como se ha dicho la publicación había cesado en junio de 1943, ya avanzado el año 1944 seguía apareciendo en las páginas de
}

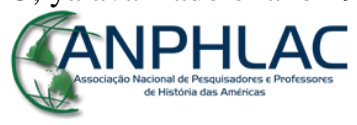

Revista Eletrônica da ANPHLAC, ISSN 1679-1061, №. 19, p. 72-103, jul./dez., 2015. http://revista.anphlac.org.br 
El número inaugural incluye una declaración de principios que sigue los lineamientos planteados en la presentación de la revista previa. Con el título de "Al lector", la publicación presenta de modo resumido sus intenciones:

Correo Literario aspira a ser un periódico de mayoría, al servicio de la cultura hispanoamericana, difundiendo sus valores en cuanto esté al alcance de sus posibilidades.

Sus páginas irán reflejando las inquietudes más candentes a lo largo de América, tanto las propias y características del continente, como las de los diferentes grupos de desterrados acogidos a la generosidad de estas tierras. [...] Correo Literario, nace sin compromiso de empresa, siendo en sí mismo una empresa independiente, sin fines comerciales a no ser los necesarios para su existencia. Lo cual garantiza -salvo nuestra capacidad de acierto-, nuestra independencia crítica y nuestra imparcialidad informativa.

Estamos convencidos de que, para un propósito así, hemos de encontrar la más amplia y fervorosa colaboración. Con ella contamos para realizar nuestra idea primordial: Dotar al movimiento cultural de habla española, del instrumento de difusión que haga posible un constante intercambio a través de un correo diligente y leal. $\left(\mathrm{n}^{\circ} 1, \mathrm{p} .1\right)$

Estas líneas ponen de relieve la orientación americanista de la publicación, en consonancia con la voluntad de los exiliados españoles de integrarla al campo cultural del país y del continente receptores ${ }^{23}$. Dicha orientación se hace patente no sólo en la atención a la actividad cultural (literaria, artística, editorial) de las naciones latinoamericanas sobre todo, aunque no exclusivamente, de la Argentina-, sino además en la nómina de colaboradores.

El grupo directivo estaba compuesto íntegramente por colaboradores de De Mar a Mar: los directores eran Arturo Cuadrado, Luis Seoane y Lorenzo Varela, y el secretario Javier Farías. Junto a estos y otros exiliados como Rafael Dieste, Francisco Ayala o Clemente Cimorra, la publicación también recibe el aporte de escritores argentinos -por ejemplo: Alberto Girri, Ulyses Petit de Murat, Cayetano Córdova Iturburu-, y, en menor medida, de firmas uruguayas -Juana de Ibarbourou, Esther de Cáceres, Enrique Amorim, entre otros- y brasileñas -tales los casos de Mario de Andrade, Newton Freitas, Vinicius de Moraes, etc.

Si bien otorgó más lugar a la crítica de las artes plásticas, cine y teatro que su

Correo Literario la publicidad que invitaba a los lectores a suscribirse a De Mar a Mar. Esto además podría plantear una posible explicación sobre las causas del cierre de la revista.

${ }^{23}$ Las relaciones de Correo Literario con el campo cultural argentino en el contexto de la Segunda Guerra Mundial ha sido analizado en un trabajo de reciente publicación (GERHARDT, 2014).

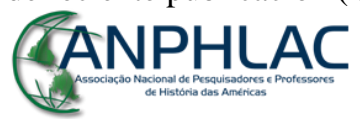

Revista Eletrônica da ANPHLAC, ISSN 1679-1061, №. 19, p. 72-103, jul./dez., 2015. http://revista.anphlac.org.br 
antecesora, Correo Literario continuó dando un lugar preponderante a la literatura y más aún a la crítica literaria, a cuya defensa y promoción la redacción dedicó varios textos. La crítica ocupaba la sección "Libros y autores", que incluía: una nota bibliográfica extensa, cercana al ensayo, generalmente a cargo de Varela o Cuadrado; de seis a doce reseñas, en las que se prestó especial atención a las ediciones realizadas por los españoles en Buenos Aires; y noticias breves sobre libros recientemente publicados o de próxima aparición, que no llevaban firma, acompañadas en ocasiones de novedades relacionadas como aperturas de librerías o instalaciones editoriales.

Al igual que en De Mar a Mar, esta sección se proyectaba en las otras páginas de Correo Literario, en la medida en que las obras objeto de la crítica pertenecían muchas veces a las editoriales que publicaban sus anuncios en la misma revista: Nova, Poseidón, Losada, El Ateneo y Sudamericana, a las que se sumaba la Imprenta López.

La fuerte presencia de la crítica literaria y la publicidad editorial en Correo Literario podría leerse en relación con las casas editoras a las que se hallaban ligados el grupo directivo y sus colaboradores, teniendo en cuenta el lugar que otorgan a la crítica y a las revistas literarias en los circuitos de edición, circulación y difusión de los libros, de acuerdo con la siguiente nota de la redacción, publicada en el número 3, sin firma, bajo el encabezado "Premáticas y desahogos":

El estruendoso éxito de una obra depende: un diez por ciento de la editorial, un veinte por ciento de la publicidad, un veinte por ciento de la crítica literaria de la gran prensa seria, un cinco por ciento de las revistas literarias de minoría ${ }^{24}$, un treinta por ciento del distribuidor y de los libreros, un cinco por ciento de la crítica honesta. El restante diez por ciento depende, a partes iguales, del acierto del título y del valor verdadero del libro. ( $\mathrm{n}^{\circ} 3$, p. 2)

\footnotetext{
${ }^{24}$ Recuérdese que, según el texto de presentación antes citado, “Correo Literario aspira a ser un periódico de mayoría".
}

\section{GANPHLAC}

Revista Eletrônica da ANPHLAC, ISSN 1679-1061, №. 19, p. 72-103, jul./dez., 2015. http://revista.anphlac.org.br 


\section{Imagen 8}

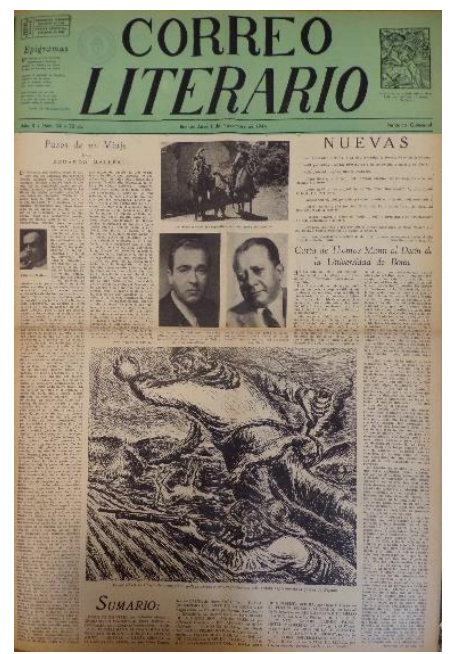

Fonte: Correo Literario, noviembre de 1944

Los vínculos entre Correo Literario y otros agentes del campo editorial de la época se vuelven aún más explícitos en el balance del primer año de publicación, donde además se vuelve a afirmar la intención de integrar la revista en el ámbito local, argentino y americano. La "Carta abierta" del número 24, del $1 .^{\circ}$ de noviembre de 1944, destaca:

Las casas editoras, imprentas y librerías argentinas prestaron también su ayuda al empeño de sostener un periódico íntegramente literario. Para que quede constancia de nuestro agradecimiento, citaremos especialmente algunas firmas: Imprenta López, la Editorial Poseidón, la Editorial Losada, la Editorial Nova, la librería El Ateneo, que nos apoyaron lealmente desde nuestra aparición. $\left(n^{\circ} 24\right.$, p. 2)

Esta declaración no sólo pone en escena una solidaridad recíproca entre estas editoriales, imprentas y librerías, por un lado, y Correo Literario, por el otro, que podría a su vez incidir en las noticias bibliográficas y reseñas incluidas en la sección "Libros y autores" ${ }^{\prime 25}$. Además, permitiría explicar al menos en parte el creciente interés por la

\footnotetext{
${ }^{25}$ Algunas suspicacias en este sentido parece haber despertado el tono de la sección bibliográfica en los lectores del momento, a juzgar por la nota en la que, bajo el título "Premáticas y desahogos", la redacción acusa recibo de sus reclamos: "Si nos gustara el escándalo podríamos hacer en Correo Literario una sección de verdadero éxito, publicando con pelos y señales las quejas que verbalmente llegan por nuestra 'falta de agresividad' en los comentarios de libros. Pero ni nos atrae el escándalo por sí mismo ni queremos aprovecharnos de un instante de sinceridad de las gentes" $\left(\mathrm{n}^{\circ} 9, \mathrm{p} .2\right)$.
}

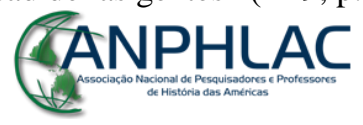

Revista Eletrônica da ANPHLAC, ISSN 1679-1061, №. 19, p. 72-103, jul./dez., 2015. http://revista.anphlac.org.br 
industria editorial que se fue haciendo paulatinamente más notorio en la revista, ya que de la marcha de la industria dependía no poco la suerte de la publicación periódica. A partir del número 31, Correo Literario dio lugar a una sección titulada "El mercado de los libros", de irregular frecuencia, firmada con seudónimos y dedicada a registrar el curso de la actividad y a explorar las causas de las alzas y las bajas. El texto que presenta la sección, firmado por "Best Seller", puntualiza: "Nos interesa auscultar la opinión pública [...] vamos a dar periódicamente a nuestros lectores lo que los cronistas de las bolsas de comercio llaman "impresión del mercado"” ( $n^{\circ} 31$, p. 7).

La última entrega de "El mercado de los libros", firmada por "Tournebroche" aparece en el número $37 \mathrm{y}$ da cuenta de lo que califica como un "verdadero colapso" de la venta de libros, augurando de todos modos una pronta recuperación ( $n^{\circ} 37$, p. 7). En el número siguiente, precisamente, la "Carta abierta" anuncia el cambio en la frecuencia de publicación: “Correo Literario se repliega a una nueva modalidad. Desde hoy hasta otros momentos se convertirá circunstancialmente en un órgano mensual" ( $n^{\circ} 38$, p. 2). Finalmente, el número 40 (01/09/1945) fue el último de Correo Literario. ${ }^{26}$

\footnotetext{
${ }^{26}$ Con respecto a las causas del cierre de Correo Literario, existen diferentes hipótesis. Por un lado, Xesús Alonso Montero (1994, p. 9) sostiene que el avance de la Segunda Guerra Mundial habría alimentado las expectativas depositadas en la destitución de Franco y el retorno de los exiliados, incluido el grupo que llevaba adelante el quincenario. Por otro lado, más recientemente, Beatriz Sarlo sugiere, como causa del cese, una persecución política por parte de "la Argentina peronista, aquel otro país que sólo muy eventualmente, sólo si se perseguía a alguna publicación o se la cerraba, como al parecer sucedió con Correo Literario, se tocaba con el mundo intelectual y artístico en el que se movía Seoane" (2012, p. 39; cursivas de la autora). Extendiendo la perspectiva en el tiempo, en ambos sentidos, Emilia de Zuleta se refiere al derrotero del proyecto iniciado con De Mar a Mar y continuado por Correo Literario, señalando que "este programa habría de naufragar por razones de orden internacional y local. Primero, las crecientes disensiones entre los "pueblos libres" y, más particularmente, el repliegue de los mismos frente al agresivo imperialismo soviético, cuya primera consecuencia fue, junto con otros factores como la habilidad política de Franco, la atribución de un nuevo papel a España en el orden internacional. En el orden local, ya hemos señalado que el surgimiento del peronismo, en 1945, produjo un cambio radical en las condiciones de vida del intelectual de Buenos Aires y, lo que fue no menos decisivo, un nuevo reagrupamiento de tendencias y figuras, tanto en lo ideológico como en lo intelectual" (1983, p. 160-161).
}

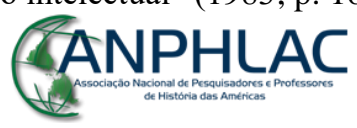

Revista Eletrônica da ANPHLAC, ISSN 1679-1061, №. 19, p. 72-103, jul./dez., 2015. http://revista.anphlac.org.br 


\section{Imagen 9}

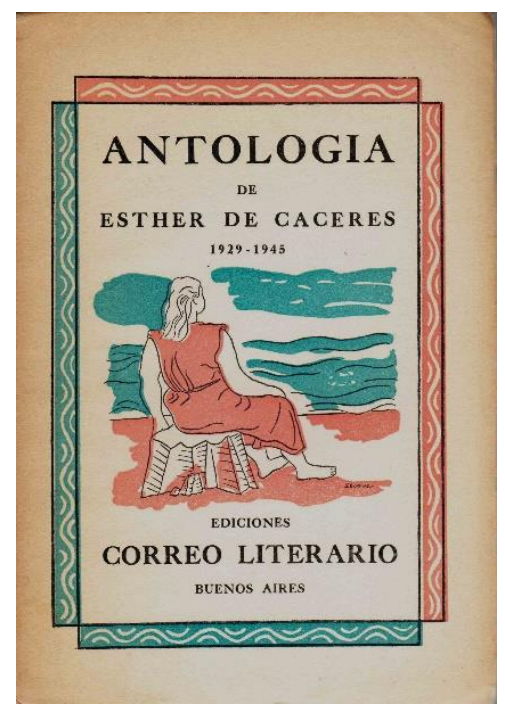

Fonte: Antología (1929-1945) de Esther de Cáceres, 1945

En diciembre de 1945, meses después de la aparición del último número de Correo Literario, se imprimió el libro Antología (1929-1945) de Esther de Cáceres, que sería el único efectivamente publicado por el sello Ediciones Correo Literario de que tengamos noticia, aunque previamente, en el número 29 del 15 de enero de 1945, una publicidad anuncia, en las páginas mismas del quincenario, la aparición de Llanto meditado de Alberto Girri como "el primer libro de poesía con el cual inicia la serie de publicaciones Correo Literario".

El volumen de Esther de Cáceres estaba ilustrado por Luis Seoane y prologado por un poema de Rafael Dieste, y su distribución estaba a cargo de la Editorial Nova.

\section{Cabalgata (1946-1948)}

Meses después, el $1^{\circ}$ de junio de 1946, una reseña de la Antología de Esther de Cáceres, firmada por José González Carbalho ${ }^{27}$, fue incluida en el número 0 de Cabalgata, que en el subtítulo se definía como "Quincenario popular. [de] Espectáculos, literatura, noticias, ciencias, artes". Tanto este subtítulo como la periodicidad que indica cambiarán a partir del número 13, de noviembre de 1947, cuando, tras una interrupción

\footnotetext{
${ }^{27}$ Escritor argentino hijo de emigrantes gallegos que firma gran parte de los textos de crítica literaria de la primera época de Cabalgata.
}

\section{GANPHLAC}

Revista Eletrônica da ANPHLAC, ISSN 1679-1061, №. 19, p. 72-103, jul./dez., 2015. http://revista.anphlac.org.br 
de siete meses, comienza la segunda época de la que ahora se define, en subtitulado, como "Revista mensual de artes y letras". El financiamiento de la publicación corría por cuenta del ya mencionado Joan Merli, marchante de arte y editor catalán residente en la Argentina, director de la editorial Poseidón, quien a partir del séptimo número de Cabalgata figuró como director de la revista, aunque ya en el mismo número inicial, que salió a la luz pero no a la venta, una nota sin firma anuncia brevemente que

\begin{abstract}
Ha partido para Estados Unidos, haciendo diversas escalas en las capitales de Sudamérica, el señor Joan Merli, distinguido crítico de arte que está al frente de la Editorial Poseidón y de la empresa editora de Cabalgata.

Nadie mejor que él para llevar a lo largo de América el saludo de quienes animan esta nueva empresa. Gracias a su intensa labor y a su sensibilidad de verdadero amante del arte y de las letras, hay en América latina una gran editorial de arte y -ahora- un quincenario que ha de ser expresión del gran movimiento intelectual que se viene acrecentando en nuestro continente, una de cuyas expresiones indudables es el desarrollo asombroso de la industria argentina del libro. $\left(\mathrm{n}^{\circ} 0, \mathrm{p} .15\right)$
\end{abstract}

\title{
Imagen 10
}

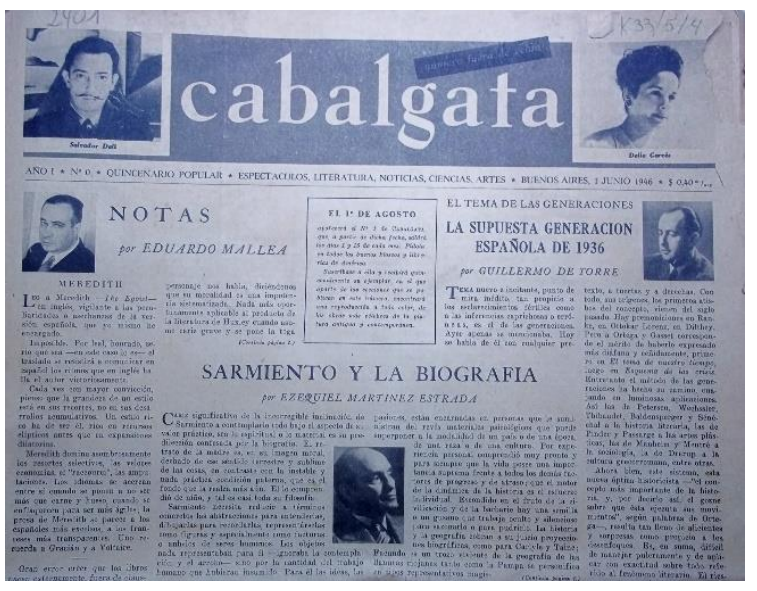

Fonte: Cabalgata, junio de 1946

Sin embargo, junto a esta figura visible, en la dirección de la revista se encontraban, nuevamente, Lorenzo Varela como director literario y Luis Seoane como director artístico, responsable de la diagramación y el diseño de la publicación, según se desprende de la correspondencia intercambiada por estos dos con diferentes corresponsales en torno a las colaboraciones para cada número. Así, por ejemplo, el 24 de septiembre de 1946, Attilio Rossi, le recuerda a Seoane que

\section{CANPHLAC}

Revista Eletrônica da ANPHLAC, ISSN 1679-1061, №. 19, p. 72-103, jul./dez., 2015. http://revista.anphlac.org.br 
en mi carta anterior dirigida a ti y a Varela confirmaba el encuentro de un colaborador ideal para Cabalgata, especifícame las condiciones [...] He visto el número 0 de Cabalgata. Hermosísimo y hallado el título. Me suena una de esas magistrales "trovata" de Dieste. Bueno el material y seria y equilibrada la compaginación. Muchas gracias por la nota dedicada a mí... ${ }^{28}$

El artista gráfico italiano, uno de los que afianzó los conocimientos de las artes editoriales en Seoane (PÉREZ RODRÍGUEZ, 2003, p. 37), se refiere a la nota sin firma publicada en ese mismo número 0 que, bajo el título de "Attilio Rossi" y con motivo de su partida a Italia, recuerda "que desde hace poco más de diez años venía consagrando lo mejor de sus actividades en este país al renacimiento gráfico del libro" y destaca sus trabajos para la 'Colección Austral' de Espasa Calpe, y las editoriales Nova, Losada y Pleamar $\left(n^{\circ} 0\right.$, p. 14$){ }^{29}$

Cabe recordar en este punto que tanto Varela como Seoane habían trabajado, y por entonces lo seguían haciendo, para la editorial de Merli, éste como ilustrador y maquetador, y aquél como traductor y autor de libros de crítica de arte y literaria (e incluso como contable y administrativo en momentos de necesidad económica). Con estos tres nombres a la cabeza, aunque sin mencionar a ninguno de ellos, sale el número 0 de Cabalgata, donde, del mismo modo que en los casos anteriores, la redacción de la revista hace una breve declaración inicial, afirmando la intención de integrarse en el campo cultural local, nacional y continental: "La idea que anima Cabalgata es hacer en la Argentina una gran revista para todo el continente. Una revista que sea expresión de todas las actividades de la cultura americana y universal" $\left(n^{\circ} 0\right.$, p. 1$)$.

De acuerdo en parte con este objetivo, el grupo de colaboradores estaba compuesto mayormente por escritores argentinos y por exiliados, entre los que se contaban, además

\footnotetext{
${ }^{28}$ Se refiere Rossi a una carta enviada el 12 de agosto de ese mismo año, que se cierra con saludos a Joan Merli, y en la que les dice: "No he recibido aún la nueva revista pero de una carta de Perrota sé que se llama Cabalgata. El título es hermoso. He encontrado el colaborador que ustedes me pedían". En una carta posterior, del 11 de enero de 1947, Rossi escribe: "Cabalgata me gusta[,] he visto hasta ahora los números el cero y el N.2 [sic]. Yo estoy coleccionando fotos dramáticas de destrucciones de monumentos célebres que pueden interesar a Cabalgata". Las tres cartas citadas se encuentran en el archivo de la Fundación Luis Seoane de A Coruña, donde han sido consultadas.

${ }^{29}$ En la "Breve crónica en relación conmigo y las artes gráficas", escrito como introducción a su Segundo libros de tapas de 1957, Luis Seoane insiste en el papel destacado de Rossi en la industria editorial argentina: "Attilio Rossi abandonó la Italia de Mussolini donde había dirigido con Carlo Dradi 'Campo gráfico' en Milán, luego de participar en todos los movimientos renovadores de la tipografía y del arte gráfico en esa ciudad. [...] Rossi trajo al libro argentino su amor a la medida, su rigor geométrico y, con sus grandes conocimientos técnicos, un afán constante de experimentación" (reproducido en: SEOANE, 1994, p. 33).
}

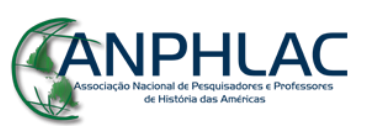

Revista Eletrônica da ANPHLAC, ISSN 1679-1061, №. 19, p. 72-103, jul./dez., 2015. http://revista.anphlac.org.br 
de los ya citados directores, otros nombres en común con las publicaciones previas, como Arturo Serrano-Plaja y José Otero Espasandín. A ellos se sumaron firmas como las de Guillermo de Torre, de notable actividad editorial en Espasa Calpe y Losada (LARRAZ, 2009), y con presencia en el catálogo de Poseidón, y Ramón Gómez de la Serna, uno de los escritores dilectos del editor Merli por aquellos años (FERNÁNDEZ, 2011).

El número 1 de Cabalgata, publicado el $1^{\circ}$ de octubre de 1946, da cuenta de un comienzo exitoso en relación con aquellos objetivos planteados en la entrega anterior, superando incluso las expectativas, de acuerdo con lo afirmado en una breve "Noticia" sin firma:

Editores, libreros, escritores y todos cuantos de uno $\mathrm{u}$ otro modo tienen relación con las actividades espirituales nos han hecho llegar sus felicitaciones y su promesa de colaboración en la difícil empresa que se propone realizar Cabalgata.

Superando el cálculo inicial de la publicidad que era presumible esperar para un primer número como es el presente, nos hemos visto obligados a alterar el plan general y a suprimir o mermar secciones que en números sucesivos alcanzarán su verdadera medida. $\left(\mathrm{n}^{\circ} 1\right.$, p. 2$)$

Prácticamente la totalidad de los anuncios publicitarios de este número, así como de los posteriores de la revista, se refieren a las editoriales, librerías e imprentas que, una vez más, se hallan ligadas a Cabalgata: Nova, Editorial Atlántida, Argos, Losada, Sudamericana, Imprenta López, Pleamar, Amorrortu (en cuyos talleres se imprime la revista) y Poseidón. En este caso, además, la revista incluía en cada número una pequeña lámina de regalo, con obras de pintores sobre los que la editorial de Merli había editado o editaría monografías. A estas firmas se suman otros sellos americanos como los mexicanos Hermes (filial de Sudamericana) y Fondo de Cultura Económica. A su vez, los libros de estas y aquellas editoriales encuentran lugar en los textos de crítica literaria y en las noticias de la actualidad editorial.

A semejanza de De Mar a Mar y Correo Literario, junto a las artes plásticas, el cine, el teatro y la música, Cabalgata incluyó una sección bibliográfica compuesta por notas breves, con un propósito de difusión, acerca de obras publicadas sobre todo en la Argentina, y, particularmente, por Losada, Emecé, Sudamericana, Poseidón y Atlántida. Esta sección bibliográfica irá incrementando significativamente sus dimensiones sobre

\section{GANPHLAC}

Revista Eletrônica da ANPHLAC, ISSN 1679-1061, №. 19, p. 72-103, jul./dez., 2015. http://revista.anphlac.org.br 
todo a partir de la segunda época. ${ }^{30}$

Pero además, desde sus primeras entregas, la revista incluyó una sección dedicada al mercado de la edición de libros, llamada "Mundo editorial", en cuyas páginas fue publicada una serie de entrevistas a diferentes agentes del campo (editores, impresores y libreros), acerca de los problemas de la industria editorial en general, y sobre los proyectos de sus respectivas empresas. Entre los primeros entrevistados se encuentran: Gonzalo Losada, de Editorial Losada ( $\mathrm{n}^{\circ}$ 1), Daniel Cossío Villegas, del Fondo de Cultura Económica ( $\mathrm{n}^{\circ}$ 1); Antonio López Llausás, de Sudamericana y Hermes ( $\mathrm{n}^{\circ}$ 3); y José López Soto, de la Imprenta López ( $\mathrm{n}^{\circ}$ 5), quien defiende el lugar de la crítica literaria y destaca su papel en el desarrollo del mercado editorial: "El periodismo debe [...]dar a la crítica literaria toda la importancia que ésta merece. Si la industria editorial necesita más páginas de información bibliográfica, el periodismo debería brindarla”.

Otro de los entrevistados es Jorge D’Urbano Viau $\left(n^{\circ} 2\right)$, anunciante desde el $n^{\circ}$ 0 de la revista, citado en su calidad no sólo de librero sino también de Secretario de la Cámara Argentina del Libro y Presidente del Club El Libro del Mes, quien a partir del $\mathrm{n}^{\circ}$ 5 se convertirá en colaborador regular de Cabalgata.

En el número 16, de febrero de 1948, le tocará el turno al propio editor de la revista, Joan Merli, en calidad de director de la Editorial Poseidón, quien, interrogado por “O.H.”, responde, como adelanta el título, "Sobre el candente problema de la industria editorial”, caracterizando del siguiente modo el panorama local: "La industria argentina del libro en la actualidad carece de mercados. El país, la Argentina, consume un porcentaje insignificante de la producción. Hay que crear un consumo interno, pero para eso es necesario que antes se abran librerías en el interior y que contemos con un ejército de vendedores de libros" ( ${ }^{\circ} 16$, p. 13).

Cabe pensar que la intervención de Cabalgata en el campo cultural local apunta a revertir este aspecto del panorama. Pero, al mismo tiempo, podría considerarse que este "candente problema de la industria editorial" es un factor determinante del fin de la

\footnotetext{
${ }^{30}$ Es en esta segunda etapa cuando tiene una participación en la sección bibliográfica un joven Julio Cortázar, quien ya había realizado tareas de traducción para Nova (v. supra), y por entonces estaba estrechamente relacionado con la industria editorial por las funciones desempeñadas en la Cámara Argentina del Libro.
}

\section{CANPHLAC}

Revista Eletrônica da ANPHLAC, ISSN 1679-1061, №. 19, p. 72-103, jul./dez., 2015. http://revista.anphlac.org.br 
publicación $^{31}$, teniendo en cuenta su estrecho vínculo con el mercado de los libros, en momentos en que la industria comenzaba a experimentar serias dificultades en su desarrollo (DE SAGASTIZÁBAL, 1995, pp. 116-117). Finalmente, en el número 21, de julio de 1948, con una nota titulada "Cabalgata deja de publicarse" la revista se despidió definiéndose a sí misma como "portavoz del libro argentino y eco de sus problemas" ( ${ }^{\circ}$ 21, p. 8).

En el panorama editorial argentino, y más precisamente en la considerada "época de oro" de dicha industria, el año 1947 es considerado como un "punto de referencia" (RIVERA, 1998, p. 120-121): por un lado, la industria atraviesa uno de sus mejores momentos, tanto por la calidad de las editoriales en lo que respecta a materiales y catálogos, como por la cantidad de ejemplares editados; pero, por otro lado, se presentan problemas que se irán acrecentando en los años posteriores, tales como la falta de divisas en los países latinoamericanos para el pago de los libros importados desde la Argentina, los problemas del transporte y distribución de los libros, y el aumento de la mano de obra.

En el caso particular abordado por el presente trabajo, entre fines de $1947 \mathrm{y}$ principios de 1948 vienen a coincidir el cese de Cabalgata, el final del proyecto de Seoane y Cuadrado en Nova, y la desvinculación de Dieste de la 'Biblioteca Billiken' y la 'Colección Oro' en la Editorial Atlántida, una coincidencia en la que, sin perder de vista la coyuntura particular de la industria del libro argentina, también cabe leer la íntima conexión de estos proyectos editoriales, y los cambios en las relaciones de sus promotores entre sí y con el país de acogida. Para ese entonces, Lorenzo Varela ya se encontraba residiendo en Montevideo desde 1947, y Rafael Dieste preparaba el viaje que lo llevaría a Cambridge, donde permanecerá desde principios de 1949 hasta 1952. Y mientras Arturo Cuadrado se quedaba en Buenos Aires tratando de mantener a flote la joven editorial Botella al Mar, Luis Seoane daba inicio a una gira que lo llevaría durante un año con su obra plástica por las principales capitales europeas.

\footnotetext{
31 Tal como lo hacen, en su clásico estudio, Lafleur, Provenzano y Alonso (2006, p. 23) al explicar su cierre por falta de avisadores.
}

\section{GANPHLAC}

Revista Eletrônica da ANPHLAC, ISSN 1679-1061, №. 19, p. 72-103, jul./dez., 2015. http://revista.anphlac.org.br 


\section{Referencias bibliográficas}

ALONSO MONTERO, Xesús. Cincuentenario de Correo Literario (Buenos Aires, 19431945). In: Correo Literario [edición facsimilar]. A Coruña: Ediciós do Castro, 1994, pp. 7-10.

BORELLO, Rodolfo. Autores, situación del libro y entorno material de la literatura en la Argentina del siglo XX. Cuadernos Hispanoamericanos, n. 322-323, pp. 35-52, 1997.

BOTTARO, Raúl. La edición de libros en Argentina. Buenos Aires: Troquel, 1964.

CAUDET, Francisco. El exilio republicano español. Las revistas literarias (1939-1971). Alicante: Universidad de Alicante, 2007.

DE DIEGO, José Luis (Dir.). Editores y políticas editoriales en Argentina, 1880-2000. Buenos Aires: Fondo de Cultura Económica, 2006.

DE SAGASTIZÁBAL, Leandro. La edición de libros en la Argentina. Una empresa de cultura. Buenos Aires: Eudeba, 1995.

DEVOTO, Fernando. Cultura y política entre dos mundos: el exilio gallego en la Argentina, los debates intelectuales y las tramas de sociabilidad (1936-1963). In: DEVOTO, F.; VILLARES R. (Eds.). Luis Seoane entre Galicia y la Argentina. Buenos Aires: Biblos, 2012, pp. 165-198.

DIESTE, Rafael. Obras Completas V. Epistolario. Edición de Xosé Luis Axeitos. A Coruña: Ediciós do Castro, 1995.

FERNÁNDEZ, Pura. El epistolario de Ramón Gómez de la Serna y Joan Merli (19421950): hacia los libros creadores. Bulletin of Spanish Studies, Liverpool, Vol. LXXXVIII, n. 7-8, pp. 287-298, 2011.

GERHARDT, Federico. "Entre la prensa y el libro, entre España y la Argentina. Crítica literaria y mercado editorial en la revista De Mar a Mar. In: ASTUTTI, A.; GARBATZKY, I.; GASPARRI, J. (Coords.). Actas del III Congreso Internacional Cuestiones Críticas. Rosario: Facultad de Humanidades y Artes, Universidad Nacional de Rosario, 2013. Disponible en: http://www.celarg.org/int/arch_publi/gerhardt_federicocc.pdf $>$. Acceso en: 20 dic. 2014.

\section{GANPHLAC}

Revista Eletrônica da ANPHLAC, ISSN 1679-1061, №. 19, p. 72-103, jul./dez., 2015. http://revista.anphlac.org.br 
GERHARDT, Federico. "La fe activa en el provenir triunfante de la libertad". La esperanza del retorno en una revista del exilio español en Buenos Aires: Correo Literario (1943-1945). In: LÓPEZ GARCÍA, J. R.; MONTIEL RAYO, F.; RODRÍGUEZ RODRÍGUEZ, J. (Eds.). El exilio republicano de 1939. Viajes y retornos. Sevilla: GEXEL-Renacimiento, 2014, pp. 569-577.

GERHARDT, Federico. Asociacionismo gallego y mercado del libro en la Buenos Aires del medio siglo: dos proyectos editoriales de Luis Seoane. Madrygal. Revista de Estudios Gallegos, Madrid, vol. 18, pp. 457-467, 2015.

GETINO, Octavio. Las industrias culturales en la Argentina. Dimensión económica y políticas públicas. Buenos Aires: Colihue, 1995.

LAFLEUR, Héctor; PROVENZANO, Sergio; ALONSO, Fernando. Las revistas literarias argentinas (1893-1967). $3^{\text {a }}$ edición. Buenos Aires: El 8vo. Loco, 2006.

LARRAZ, Fernando. Los exiliados y las colecciones editoriales en Argentina (19381954). In: PAGNI, A. (Ed.). El exilio republicano español en México y Argentina. Historia cultural, instituciones literarias, medios. Madrid-Frankfurt: IberoamericanaVervuert-Bonilla Artigas Editores, 2011, pp. 129-144.

LARRAZ, Fernando. Política y cultura. Biblioteca Contemporánea y Colección Austral, dos modelos de difusión cultural". Orbis Tertius. Revista de Teoría y Crítica Literaria, La Plata, n. $15,2009 . \quad$ Disponible en: $\langle$ http://www.orbistertius.unlp.edu.ar/article/view/OTv14n15d01/5007>. Acceso en: 10 mar. 2015.

MACCIUCI, Raquel. Intelectuales españoles en el campo cultural argentino. Francisco Ayala, de Sur a Realidad (1939-1950). In: PAGNI, A. (Ed.). El exilio republicano español en México y Argentina. Historia cultural, instituciones literarias, medios. MadridFrankfurt: Iberoamericana-Vervuert-Bonilla Artigas Editores, 2011, pp. 159-188.

MARTÍNEZ, María Victoria. Los intelectuales españoles en el exilio en la Argentina y las condiciones de su inserción en su nueva realidad. Los colaboradores españoles en La Nación de Buenos Aires, en la década de 1939-1949. Borradores. Revista del Departamento de Lengua y Literatura de la Facultad de Ciencias Humanas, Río Cuarto, Segunda época, n. 7, 2007. Disponible en: < https://www.unrc.edu.ar/publicar/borradores/Vol7/pdf/Los\%20intelectuales\%20espanol es $\% 20 \mathrm{en} \% 20 \mathrm{el} \% 20 \mathrm{exilio} \% 20 \mathrm{en} \% 20 \mathrm{la} \% 20$ Argentina, $\% 20 \mathrm{y} \% 20 \mathrm{las} \% 20$ condiciones $\% 20$ de\%20insercion\%20en\%20su\%20nueva\%20realidad.pdf>. Acceso en: 10 jun. 2015. 
PELEGRÍN, Ana. Una aproximación a los libros infantiles en el exilio español (19391977). In: PELEGRÍN, A.; SOTOMAYOR, M. V.; URDIALES, A. (Eds.). Pequeña memoria recobrada: libros infantiles del exilio del 39. Madrid: Secretaría General Técnica-MEPSYD, 2008, pp. 13-42.

PÉREZ RODRÍGUEZ, María Antonia. Análise da correspondencia entre Maruja Mallo e Alfonso Reyes (1938-1945). Madrygal. Revista de Estudos Galegos, Madrid, vol. 16, pp. 73-86, 2013a.

PÉREZ RODRÍGUEZ, María Antonia. As editoriais no exilio arxentino/Las editoriales en el exilio argentino. Galegos=Gallegos, Santiago de Compostela, n. 7, pp. 110-118, 2009.

PÉREZ RODRÍGUEZ, María Antonia. Luis Seoane a través da prensa. 1929-1979. A Coruña: Ediciós do Castro, 2003.

PÉREZ RODRÍGUEZ, María Antonia. Nova 1942-1947: una editorial de exiliados gallegos en Argentina. In: Santana, A. (Coord.). Setenta años de Cuadernos Americanos. México: Universidad Autónoma de México, 2013b, pp. 119-134.

PÉREZ RODRÍGUEZ, María Antonia. O labor de Luis Seoane na prensa. In: ANEIROS DÍAZ, R.; LÓPEZ GARCÍA, X.; PÉREZ PEREIRO, M.; FREIXANES, V. F. (Eds.). Xornalistas con opinión. 20 biografías. Vigo: Consello da Cultura Galega-Editorial Galaxia, 2007, pp. 323-338.

POCHAT, María Teresa. Editores y editoriales. In: SÁNCHEZ ALBORNOZ, N. (Comp.). El destierro español en América. Un trasvase cultural. Madrid: SiruelaSociedad Estatal Quinto Centenario-Instituto de Cooperación Iberoamericana, 1991, pp. 163-176.

REI NÚÑEZ, Luis. A travesía dun século. Biografía de Rafael Dieste. A Coruña: Ediciós do Castro, 1987.

RIVERA, Jorge. El escritor y la industria cultural. Buenos Aires: Atuel, 1998.

RODINO LALÍN, Hugo. As editoriais galegas en Bós Aires. Revista do Comisión Galega do Quinto Centenario, A Coruña, n. 1, pp. 49-71, 1989.

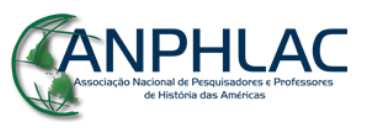

Revista Eletrônica da ANPHLAC, ISSN 1679-1061, №. 19, p. 72-103, jul./dez., 2015. http://revista.anphlac.org.br 
RODINO LALÍN, Hugo. Asociacionismo gallego en Buenos Aires. In: CLEMENTI, H. (Ed.). Inmigración española en la Argentina (Seminario 1990). Buenos Aires: Ofícina Cultural de la Embajada de España, 1991, pp. 289-314.

SARLO, Beatriz. Las Argentinas de Seoane. In: DEVOTO, F.; VILLARES R. (Eds.). Luis Seoane entre Galicia y la Argentina. Buenos Aires: Biblos, 2012, pp. 29-46.

SCHWARZSTEIN, Dora. Entre Franco y Perón. Memoria e identidad del exilio republicano español en Argentina. Barcelona: Crítica, 2001.

SCHWARZSTEIN, Dora. La llegada de los republicanos españoles a la Argentina. Estudios Migratorios Latinoamericanos, Buenos Aires, n. 37, 1997, pp. 423-447.

SEOANE, Luis (2009) [1972]. "Unha vida contada na radio. Luis Seoane dialoga con Vicky Linares é Cordova Iturburu”. Galegos=Gallegos, Santiago de Compostela, n. 7, pp. 161-180.

SEOANE, Luis. Breve crónica en relación conmigo y las artes gráficas. In: AXEITOS, X. L.; SEOANE, X. (Coords.). Luis Seoane e o libro galego na Arxentina [1937-1978]. A Coruña: Deputación Provincial de A Coruña, 1994, pp. 32-34.

VÁZQUEZ VILLANUEVA, Graciana. Política de lectura y política editoriales como programa político. Los republicanos españoles en Buenos Aires (1939-1950). El caso de Luis Seoane. In: Educ.ar. Portal educativo del Ministerio de Educación de la Argentina. Disponible en: <http://descargasapi.educ.ar/repositorio/Download/file?file_id=419d0cea-7a09-11e1-81f6ed15e3c494af>. Acceso en: 13 sept. 2014.

ZULETA, Emilia de. Los exiliados españoles en revistas literarias argentinas. In: SÁNCHEZ ALBORNOZ, N. (Comp.). El destierro español en América. Un trasvase cultural. Madrid: Siruela-Sociedad Estatal Quinto Centenario-Instituto de Cooperación Iberoamericana, 1991, pp. 183-198.

ZULETA, Emilia de. Relaciones literarias entre España y la Argentina. Madrid: Ediciones Cultura Hispánica, 1983.

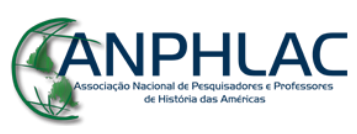

Revista Eletrônica da ANPHLAC, ISSN 1679-1061, №. 19, p. 72-103, jul./dez., 2015. http://revista.anphlac.org.br 